\title{
Phylogenetic Relationships of Marine Bacteria, Mainly Members of the Family Vibrionaceae, Determined on the Basis of 16S rRNA Sequences
}

\author{
KUMIKO KITA-TSUKAMOTO,${ }^{1 *}$ HIROSHI OYAIZU, ${ }^{2}$ KENJI NANBA, ${ }^{1}$ AND USIO SIMIDU ${ }^{1}$ \\ Ocean Research Institute, University of Tokyo, Minamidai, Nakano, Tokyo 164, ${ }^{1}$ and Faculty of Agriculture, \\ University of Tokyo, Hongo, Bunkyou, Tokyo $113,{ }^{2}$ Japan
}

\begin{abstract}
The phylogenetic relationships of 50 reference strains, mostly marine bacteria which require $\mathrm{Na}^{+}$for growth, were determined on the basis of $60016 \mathrm{~S}$ rRA nucleotides by using reverse transcriptase sequencing. Strains belonging to $\mathbf{1 0}$ genera were included (four genera of the family Vibrionaceae, the genus Aeromonas of the family Aeromonadaceae, and the genera Alteromonas, Marinomonas, Shewanella, Pseudomonas, and Deleya). The sequences were aligned, the similarity values and evolutionary distance values were determined, and a phylogenetic tree was constructed by using the neighbor-joining method. On the basis of our results, the family Vibrionaceae was separated into at least seven groups (genera and families). Vibrio marinus clearly was on a line of descent that was remote from other vibrios. As determined by the similarity and evolutionary distance values, $V$. marinus is more distantly related to the family Vibrionaceae than the members of the Aeromonadaceae are. Also, Vibrio cholerae strains formed a separate group with Vibrio mimicus at the genus level. Of 30 species of the Vibrionaceae, 17 formed a large phylogenetic cluster. The genus Listonella was found to be a heterogeneous group, and the species were distributed in various subgroups of the Vibrionaceae. The separation of the family Aeromonadaceae from the family Vibrionaceae and the separation of the genera Marinomonas and Shewanella from the genus Alteromonas were confirmed in this phylogenetic study. However, a marine Pseudomonas species, Pseudomonas nautica, was clearly separated from two terrestrial Pseudomonas species. Each group that was separated by the phylogenetic analysis had characteristic 16S rRNA sequence patterns that were common only to species in that group. Therefore, the characteristic sequences described in this paper may be useful for identification purposes.
\end{abstract}

Heterotrophic bacteria which are gram negative and motile by means of flagella are commonly isolated from marine environments and apparently are a major component of the bacterial flora of the sea. On the basis of their ability to ferment carbohydrates, these organisms can be divided into two groups. The fermentative strains have been assigned to the genera Vibrio, Listonella, Photobacterium, Colwellia (10), and Aeromonas, and the nonfermentative strains have been included in the genera Alteromonas, Pseudomonas, Alcaligenes, Deleya, Marinomonas, Shewanella, and Flavobacterium (1).

The family Vibrionaceae is one of the most important bacterial groups in marine environments. Members of this family often predominate in the bacterial flora of seawater, plankton, and fish. In a survey carried out in the West Pacific Ocean, vibrios accounted for nearly $80 \%$ of the bacterial population in surface seawater (31). Members of the Vibrionaceae are also the main organisms present in the intestinal flora of marine fish (30). In addition, some members of the Vibrionaceae are important pathogens for humans and animals.

The marine members of the Vibrionaceae have been the subject of many taxonomic studies, and this group is now the best-established marine bacterial taxon. The number of described species in the family Vibrionaceae, particularly the genus Vibrio, has been expanding rapidly. The number of Vibrio species increased from 5 in Bergey's Manual of Determinative Bacteriology in 1974 (29) to 20 in Bergey's Manual of Systematic Bacteriology in 1984 (2) and now exceeds $34(3,4,9,12-16,20,26,28,33,34,37)$. Because of

\footnotetext{
${ }^{*}$ Corresponding author.
}

the expansion of the family Vibrionaceae, it is important to establish the phylogenetic relationships among its members.

Although methods based on molecular biology, including DNA-DNA hybridization and DNA-rRNA hybridization, have been used for bacterial taxonomy for a long time, the recent development of techniques for sequencing DNA and RNA is expected to lead to a fundamental revision of microbial systematics. MacDonell and Colwell have applied the results of a sequence analysis of $5 \mathrm{~S}$ rRNAs to the taxonomy of marine bacteria, mainly members of the genus Vibrio (22).

Recently, many reports have been published on the $16 \mathrm{~S}$ rRNA sequences of bacteria and the phylogenetic relationships deduced from analyses of these sequences $(6,7,11,19$, 25). Most of the results indicate that phylogenetic relationships based on 16S rRNA sequences support the distinction among eubacteria, archaeobacteria, and eucaryota and are generally in accord with the present status of bacterial classification. Also, the phylogenetic significance of bacterial classification based on $16 \mathrm{~S}$ rRNA sequences has been recognized by many workers, and an ad hoc committee has recently recommended changes in classification (36).

In this paper we describe the phylogenetic relationships among 50 reference strains that are representative of marine bacteria, including 34 strains of the family Vibrionaceae. Most of the marine bacterial strains which we studied require $\mathrm{Na}^{+}$for growth.

\section{MATERIALS AND METHODS}

Strains and cultivation. The 50 reference strains used in this study are listed in Table 1 . These organisms were obtained from several culture collections, including the 
TABLE 1. Strains used in this study

\begin{tabular}{|c|c|c|}
\hline Taxon & Strain & Abbreviation $^{a}$ \\
\hline Aeromonas caviae & $\mathrm{JCM} 1060^{\mathrm{T}^{b}}$ & ACAV \\
\hline $\begin{array}{l}\text { Aeromonas hydrophila subsp. } \\
\text { anaerogenes }\end{array}$ & IFO $13282^{\mathrm{T}}$ & AHAN \\
\hline Aeromonas media & $\mathrm{JCM} 2385^{\mathrm{T}}$ & AMED \\
\hline $\begin{array}{l}\text { Aeromonas salmonicida subsp. } \\
\text { masoucida }\end{array}$ & IFO 13784 & ASMA \\
\hline Aeromonas veronii & ATCC $35624^{\mathrm{T}}$ & AVER \\
\hline Alteromonas espejiana & IAM 12640 & ALES \\
\hline Alteromonas haloplanktis & ATCC $14393^{\mathrm{T}}$ & ALHA \\
\hline Alteromonas nigrifaciens & IAM $13010^{T}$ & ALNI \\
\hline Deleya marina & IAM 12928 & DMAR \\
\hline Escherichia coli & & ECOL \\
\hline Listonella anguillara & IFO $13266^{\mathrm{T}}$ & LANG \\
\hline Listonella damsela & ATCC $33539^{\mathrm{T}}$ & LDAM \\
\hline Listonella pelagia & ATCC $25916^{\mathrm{T}}$ & LPEL \\
\hline Marinomonas communis & IAM $12914^{\mathrm{T}}$ & MCOM \\
\hline Marinomonas vaga & IAM $12923^{\mathrm{T}}$ & MVAG \\
\hline Photobacterium angustum & & PANG \\
\hline Photobacterium leiognathi & ATCC $25521^{\mathrm{T}}$ & PLEI \\
\hline Photobacterium phosphoreum & ATCC $11040^{\mathrm{T}}$ & PPHO \\
\hline Plesiomonas shigelloides & ATCC $14029^{\mathrm{T}}$ & PLSH \\
\hline Pseudomonas aeruginosa & IAM $1514^{T}$ & PSAE \\
\hline Pseudomonas fluorescens & IAM $12022^{\mathrm{T}}$ & PSFL \\
\hline Pseudomonas nautica & IAM $12929^{\mathrm{T}}$ & PSNA \\
\hline Shewanella putrefaciens & IAM 12079 & SPUT \\
\hline Vibrio aestuarianus & ATCC $35048^{\mathrm{T}}$ & VAES \\
\hline Vibrio alginolyticus & NCMB $1903^{T}$ & VALG \\
\hline Vibrio campbellii & ATCC $25920^{\mathrm{T}}$ & VCAM \\
\hline Vibrio carchariae & ATCC $35084^{\mathrm{T}}$ & VCAR \\
\hline Vibrio cholerae Eltor Ogawa & IID 936 & VCHOI \\
\hline Vibrio cholerae Classical Inaba & IID 467 & VCHO2 \\
\hline Vibrio cholerae Eltor Inaba & IID 1655 & $\mathrm{VCHO} 3$ \\
\hline Vibrio cholerae Classical Inaba & IID 935 & VCHO4 \\
\hline Vibrio cholerae Classical Ogawa & IID 934 & VCHOS \\
\hline Vibrio costicola & NCMB $701^{\mathrm{T}}$ & VCOS \\
\hline Vibrio diazotrophicus & ATCC $33466^{\mathrm{r}}$ & VDIA \\
\hline Vibrio fischeri & ATCC $7744^{\mathrm{T}}$ & VFIS \\
\hline Vibrio fluvialis & NCTC 11328 & VFLU \\
\hline Vibrio gazogenes & ATCC $29988^{T}$ & VGAZ \\
\hline Vibrio harveyi & ATCC $14126^{\mathrm{T}}$ & VHAR \\
\hline Vibrio hollisae & $\mathrm{JCM} 1283^{\mathrm{T}}$ & VHOL \\
\hline Vibrio logei & ATCC 15382 & VLOG \\
\hline Vibrio marinus & ATCC $15381^{T}$ & VMAR \\
\hline Vibrio metschnikovii & NCTC $8443^{\mathrm{T}}$ & VMET \\
\hline Vibrio mimicus & ATCC 33655 & VMIM \\
\hline Vibrio natriegens & $\mathrm{CCM} 2575^{\mathrm{T}}$ & VNAT \\
\hline Vibrio nereis & ATCC $25917^{\mathrm{T}}$ & VNER \\
\hline Vibrio nigripulchritudo & ATCC $27043^{T}$ & VNIG \\
\hline Vibrio ordalii & ATCC $33509^{T}$ & VORD \\
\hline Vibrio orientalis & ATCC $33934^{\mathrm{T}}$ & VORI \\
\hline Vibrio parahaemolyticus & ATCC $17802^{\mathrm{T}}$ & VPAR \\
\hline Vibrio proteolyticus & NCMB $1326^{\mathrm{T}}$ & VPRO \\
\hline
\end{tabular}

a Abbreviations are used Fig. 1 through 3.

${ }^{b} \mathrm{~T}=$ type strain.

American Type Culture Collection (ATCC), Rockville, Md.; the Czechoslovak Collection of Microorganisms (CCM); the Institute of Applied Microbiology (IAM), Tokyo, Japan; the Institute for Fermentation, Osaka (IFO), Osaka, Japan; The Institute of Medical Science (IID), Tokyo, Japan; the Japan Collection of Microorganisms (JCM), Tokyo, Japan; the National Collection of Marine Bacteria (NCMB), Alberdeen, Scotland; and the National Collection of Type Cultures (NCTC), London, England.

Strains were grown with shaking in half-strength ZoBell $2216 \mathrm{E}$ medium $(38)$ at $20^{\circ} \mathrm{C}$. Cells were harvested at approx- imately early stationary phase by centrifugation, washed with sterile TMK buffer (10 mM magnesium acetate, $25 \mathrm{mM}$ $\mathrm{KCl}, 50 \mathrm{mM}$ Tris- $\mathrm{HCl}$ [pH 7.6]), and stored at $-25^{\circ} \mathrm{C}$.

Extraction and determination of $16 \mathrm{~S}$ rRNA sequences. Cells were suspended in TMK buffer, and Macoloid solution (23)

TABLE 2. Accession numbers for partial 16S rRNA sequences of strains included in this study

\begin{tabular}{|c|c|c|c|}
\hline \multirow[b]{2}{*}{ Taxon } & \multicolumn{3}{|c|}{ Accession no. } \\
\hline & $\begin{array}{l}\text { Primer } \\
\text { R520 }\end{array}$ & $\begin{array}{l}\text { Primer } \\
\text { R920 }\end{array}$ & $\begin{array}{l}\text { Primer } \\
\text { R1400 }\end{array}$ \\
\hline eromonas caviae $\mathrm{J}$ & D11169 & D11218 & D1126 \\
\hline $\begin{array}{l}\text { Aeromonas hydrophila subsp. anaero- } \\
\text { genes IFO } 13282^{\mathrm{T}}\end{array}$ & & & \\
\hline Aeromonas media $\mathrm{JCM} 2385^{\mathrm{T}}$ & D11174 & D11223 & D11272 \\
\hline $\begin{array}{l}\text { Aeromonas salmonicida subsp. ma- } \\
\text { soucida IFO } 13784\end{array}$ & D11175 & D11124 & D112 \\
\hline Aeromonas veronii ATCC $35624^{\mathrm{T}}$ & D11176 & D11225 & D112 \\
\hline Alteromonas e & D11171 & D11220 & D1120 \\
\hline $\begin{array}{l}\text { Alteromonas haloplanktis ATCC } \\
14393^{\mathrm{T}}\end{array}$ & D11172 & D11221 & D11 \\
\hline Alteromonas nigrifaciens IAM $13010^{\mathrm{T}}$ & 173 & 222 & D1127 \\
\hline Deley & D11177 & D11226 & D112 \\
\hline Listonella anguillar & D11178 & D11227 & D112 \\
\hline Listonella damsela A & D11179 & D11228 & D11277 \\
\hline Listonella pelagia ATCC $25916^{\mathrm{T}}$ & D11180 & D11229 & D1127 \\
\hline Marinomonas communis IAM $12914^{\mathrm{T}}$ & D11181 & D11230 & D112 \\
\hline Marinomonas vaga IAM $12923^{\mathrm{T}}$ & D11182 & D11231 & \\
\hline & D11183 & D11232 & \\
\hline bacteriu & D11184 & D11233 & D112 \\
\hline
\end{tabular}
$25521^{\mathrm{T}}$

Photobacterium phosphoreum ATCC $\quad$ D11186 D11235 D11284 $11040^{\mathrm{T}}$

Plesiomonas shigelloides ATCC $\quad$ D11185 D11234 D11283 $14029^{\mathrm{T}}$

Pseudomonas aeruginosa IAM 514

Pseudomonas fluorescens IAM $12022^{\mathrm{T}}$

Pseudomonas nautica IAM $12929^{\mathrm{T}}$

Shewanella putrifaciens IAM 12079

Vibrio aestuarianus ATCC $35048^{\mathrm{T}}$

Vibrio alginolyticus NCMB $1903^{\mathrm{T}}$

Vibrio campbellii ATCC $25920^{\mathrm{T}}$

Vibrio carchariae ATCC $35084^{\mathrm{T}}$

Vibrio cholerae Eltor Ogawa IID 936

Vibrio cholerae Classical Inaba IID 467

Vibrio cholerae Eltor Inaba IID 1655

Vibrio cholerae Classical Inaba IID 935

Vibrio cholerae Classical Ogawa IID 934

Vibrio costicola NCMB $701^{\mathrm{T}}$

Vibrio diazotrophicus ATCC $33466^{\mathrm{T}}$

Vibrio fischeri ATCC $7744^{\mathrm{T}}$

Vibrio fluvialis NCTC 11328

Vibrio gazogenes ATCC $29988^{\mathrm{T}}$

Vibrio harveyi ATCC $14126^{\mathrm{T}}$

Vibrio hollisae JCM $1283^{\mathrm{T}}$

Vibrio logei ATCC 15382

Vibrio marinus ATCC $15381^{\mathrm{T}}$

Vibrio metschnikovii NCTC $8443^{\mathrm{T}}$

Vibrio mimicus ATCC 33655

Vibrio natriegens CCM $2575^{\mathrm{T}}$

Vibrio nereis ATCC $25917^{\mathrm{T}}$

Vibrio nigripulchritudo ATCC $27043^{\mathrm{T}}$

Vibrio ordalii ATCC $33509^{\mathrm{T}}$

Vibrio orientalis ATCC $33934^{T}$

Vibrio parahaemolyticus ATCC $17802^{\mathrm{T}}$

Vibrio proteolyticus NCMB $1326^{\mathrm{T}}$
D11187 D11236 D11285

D11188 D11237 D11286

D11189 D11238 D11287

$\begin{array}{lll}\mathrm{D} 11190 & \mathrm{D} 11239 & \mathrm{D} 11288\end{array}$

D11191 D11240 D11289

D11192 D11241 D11290

D11193 D11242 D11291

D11194 D11243 D11292

D11195 D11244 D11293

D11196 D11245 D11294

$\begin{array}{lll}\mathrm{D} 11197 & \mathrm{D} 11246 & \mathrm{D} 11295\end{array}$

D11198 D11247 D11296

D11199 D11248 D11297

D11200 D11249 D11298

D11201 D11250 D11299

D11202 D11251 D11300

D11203 D11252 D11301

D11204 D11253 D11302

D11205 D11254 D11303

D11206 D11255 D11304

D11207 D11256 D11305

D11208 D11257 D11306

D11209 D11258 D11307

D11210 D11259 D11308

D11211 D11260 D11309

D11212 D11261 D11310

$\begin{array}{lll}\mathrm{D} 11213 & \mathrm{D} 11262 & \mathrm{D} 11311\end{array}$

D11214 D11263 D11312

D11216 D11265 D11314 $\begin{array}{lll}\text { D11217 } & \text { D11266 } & \text { D11315 }\end{array}$
D11215 D11264 D11313 


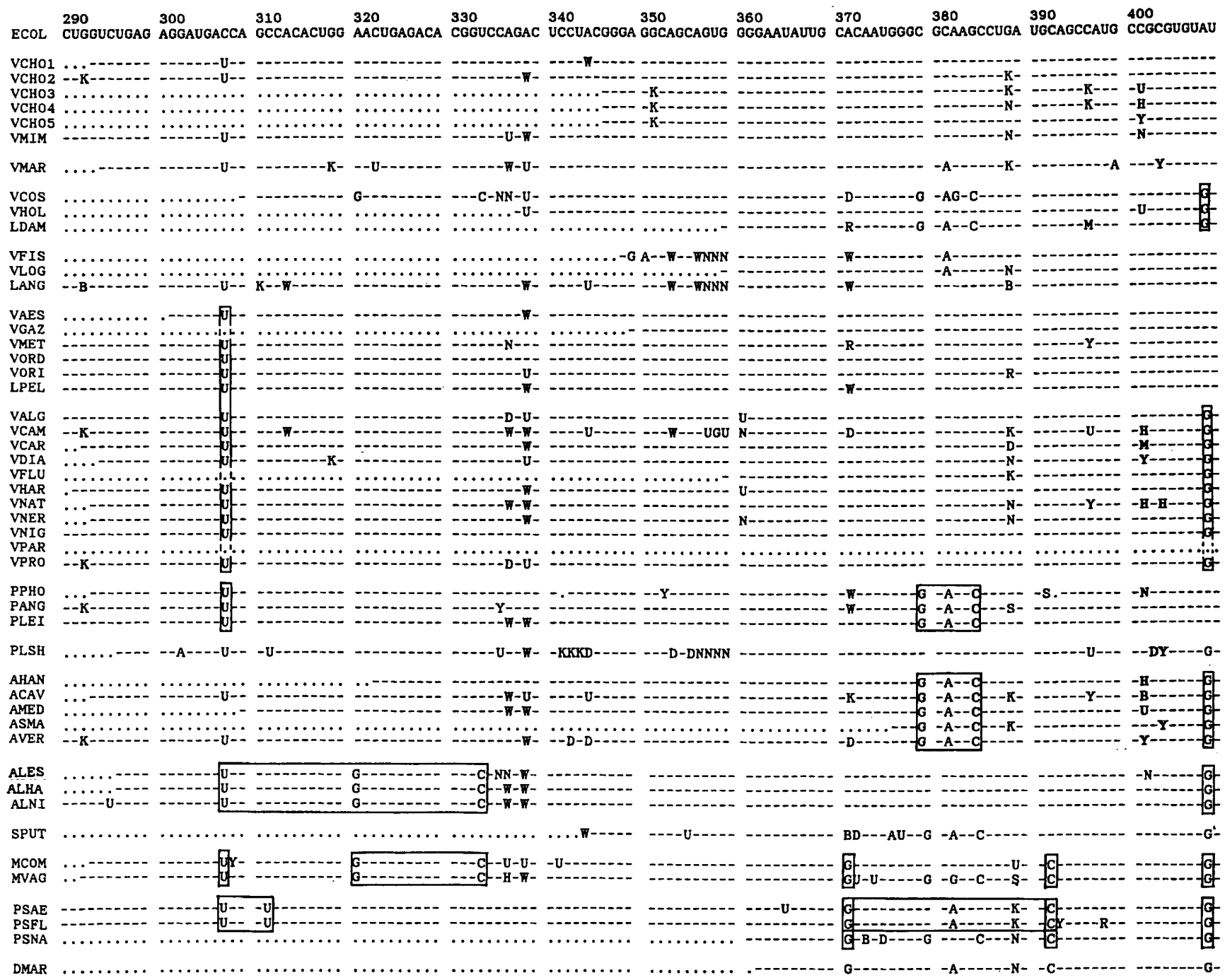

FIG. 1. Partial 16S rRNA sequences of 50 reference strains, corresponding to positions 290 to 509,690 to 904 , and 1180 to 1379 of the $E$. coli 16S rRNA sequence (5). Abbreviations for nucleotides used in the alignment: R, purine (A or G); Y, pyrimidine (C or U); $M, A$ or C; W, A or U; S, C or G; K, G or U; D, A, G, or U; H, A, C, or U; V, A, C, or G; B, C, G, or U; N, A, C, G, or U; the dots indicate padding. These abbreviations and symbol are currently under consideration by a commission of the International Union of Pure and Applied Chemistry-International Union of Biochemistry. For abbreviations of organism names, see Table 1. The portions enclosed in boxes are sequences that are common to the members of individual branching groups (Fig. 2).

was added as an RNase inhibitor. When cells which have particularly high levels of RNase activity were prepared, phenol was added along with the Macoloid solution as an additional RNase inhibitor. Nucleic acids were purified by phenol-chloroform extraction and cold isopropanol precipitation. DNA was digested with $60 \mathrm{U}$ of RNase-free DNase I (Takara Shuzo Co., Ltd.). Each RNA preparation was dried and suspended in $10 \mathrm{mM}$ Tris- $\mathrm{HCl}$ buffer $(\mathrm{pH} \mathrm{8.5)}$ at a concentration of $8 \mu \mathrm{g} / \mu \mathrm{l}$.

16S rRNA sequences were determined by using the reverse transcriptase reaction and oligonucleotide primers specific to the 16S rRNAs. For sequencing we used the protocol described by Lane et al. (18), with some modifications. Three DNA primers were used in the sequencing reactions; primer R520 covered the sequence from position 517 to position 531 (Escherichia coli numbering) (5), primer R920 covered the sequence from position 907 to position
926, and primer R1400 covered the sequence from position 1392 to position 1406 .

The reverse transcriptase sequencing reaction was stopped by adding $5 \mu \mathrm{l}$ of stop mixture (15 mM EDTA [pH $8.0]$ ), and the preparation was dried in vacuo. After a dye mixture $(0.05 \%$ bromophenol blue and $0.05 \%$ xylene cyanol in formamide) was added, the reaction mixture was heated for $3 \mathrm{~min}$ at $97^{\circ} \mathrm{C}$ before it was loaded onto the sequencing gel. A nongradient $8 \%$ polyacrylamide gel (thickness, 0.35 $\mathrm{mm}$; length, $50 \mathrm{~cm}$ ) was used for electrophoresis.

Determination of phylogenetic relationships. Sequences were initially aligned on the basis of obvious primary structure homology. The evolutionary distance per site $(K)$ was calculated as follows: $K=-(1 / 2) \ln [(1-2 P-Q)(1-$ $\left.2 Q)^{1 / 2}\right](17)$, where $P$ and $Q$ were the fractions of nucleotide sites having transition and transversion types of substitu- 


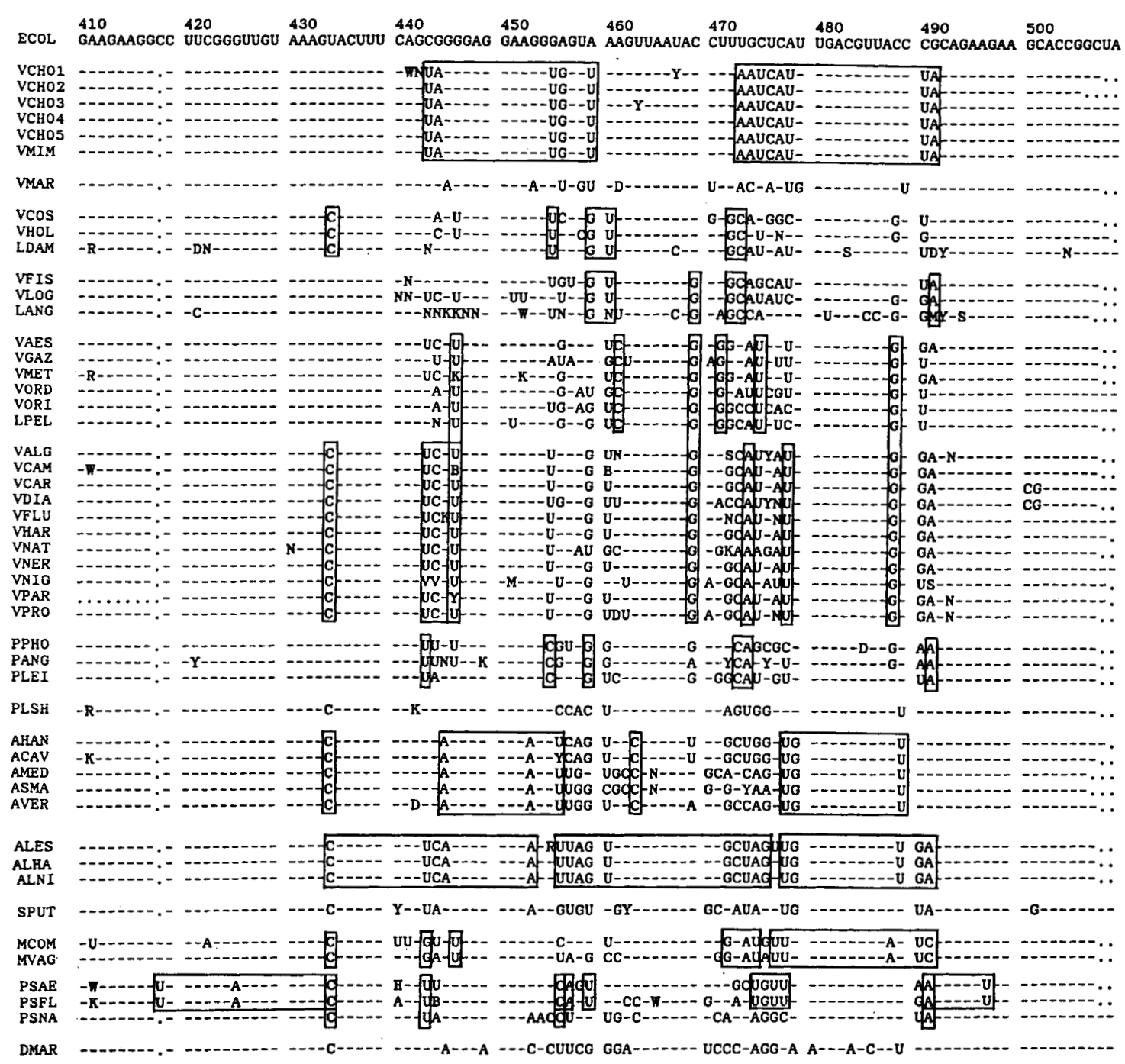

FIG. 1-Continued.

tions in two sequences, respectively. A phylogenetic tree was constructed by using the neighbor-joining method (27).

Nucleotide sequence accession numbers. The partial $16 \mathrm{~S}$ rRNA sequences reported in this paper have been deposited in the DDBJ (Mishima, Japan), EMBL (Heidelberg, Germany), and GenBank (Mountain View, Calif.) nucleotide sequence data bases under accession numbers D11169 to D11315 (Table 2).

\section{RESULTS}

Partial sequences consisting of 600 16S rRNA bases, covering base positions 290 to 509,690 to 904 , and 1180 to 1379 (Escherichia coli numbering) (5), were determined for 50 bacterial reference strains. The sequence alignments are shown in Fig. 1. An unrooted phylogenetic tree constructed from the $K$ values is shown in Fig. 2 .

According to our phylogenetic analysis, 7 of the 10 genera used in this study (the genera Aeromonas, Alteromonas, Deleya, Marinomonas, Photobacterium, Plesiomonas, and Shewanella) represent distinct isolated lines of descent. In contrast, the members of the genus Listonella were divided among several branches along with species of the genus
Vibrio. The members of the genus Pseudomonas were divided into two clearly diverse branches, and the members of the genus Vibrio occurred in five branches. A total of 30 Vibrio and Listonella strains were examined; 16 Vibrio strains and one Listonella strain constituted a large branch, and 13 strains occurred on branches that were distinct from the branch that contained the other 17 strains. In particular, Vibrio marinus was far removed from the other members of the genus Vibrio. The large cluster consisting of 17 strains could be further divided into two subgroups. One of these included Vibrio aestuarianus, Vibrio gazogenes, Vibrio meschnikovii, Vibrio ordalii, Vibrio orientalis, and Listonella pelagia; these organisms had similarity values and $K$ values ranging from 96.39 to $98.85 \%$ and from 1.02 to 3.86 , respectively. The members of the other subgroup, including 11 species belonging to the genus Vibrio, had similarity values and $K$ values that ranged from 95.78 to $99.79 \%$ and from 0.22 to 3.81 , respectively. When the data for all 17 strains were included, the similarity values and $K$ values were more than $95.32 \%$ and less than 5.06 , respectively. This finding indicates that the 17 strains constitute a fairly homogeneous group. 


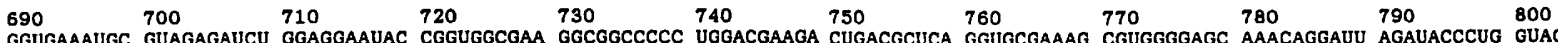

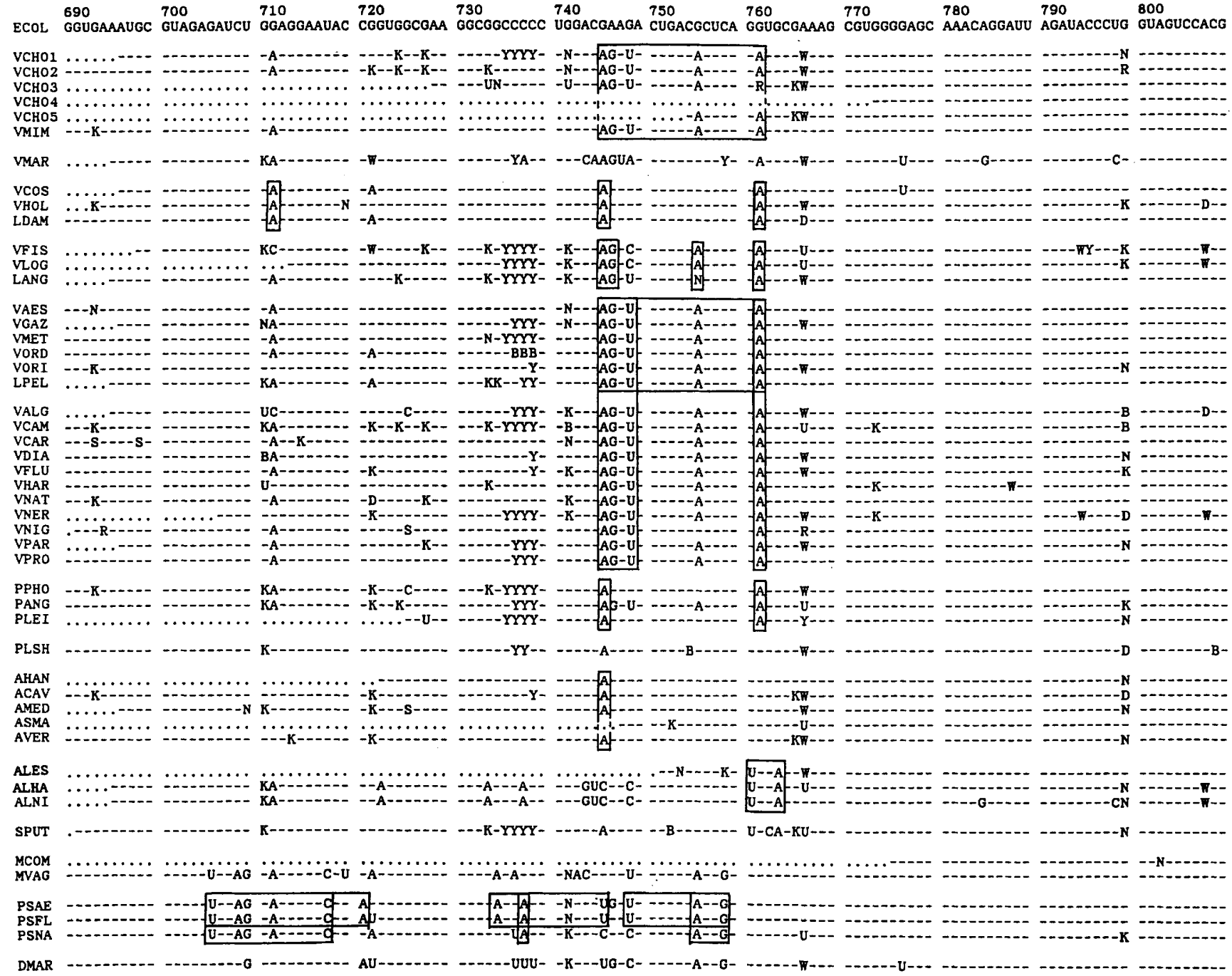

FIG. 1-Continued.

Figure 3 shows the similarity values and $K$ values for the 16S rRNA sequences of the organisms used in this study. High similarity values and low $K$ values were observed among the species in the separate groups (new genera) of the genus Vibrio. Five strains of $V$, cholerae, including two biotypes and two serotypes, formed one clearly distinguishable cluster along with Vibrio mimicus; the levels of similarity among the strains ranged from 99.06 to $100.00 \%$, and the $K$ values ranged from 0.00 to 0.78 , indicating that these organisms are very closely related. On the other hand, the distances between the $V$. cholerae- $V$. mimicus group and other vibrio groups were quite large. Three species of the genus Photobacterium were members of one branch, which was located near the large compact cluster that included 17 species of the Vibrionaceae. Vibrio fischeri, Vibrio logei, and Listonella anguillara also were on one branch near the big cluster but were quite distant from each other. The similarity value and $K$ value ranges for Listonella species were much greater than the ranges for most genera, showing that this group of organisms is heterogeneous. The similarity values and $K$ values for the genus Pseudomonas also exhibited a great deal of variability, ranging from 88.48 to $96.15 \%$ and from 4.02 to 12.95 , respectively. In this study, three
Pseudomonas species were used. Two species, Pseudomonas fluorescens and Pseudomonas aeruginosa, do not require $\mathrm{Na}^{+}$for growth, while Pseudomonas nautica does. For the two terrestrial species the similarity and $K$ values were $96.15 \%$ and 4.02 , respectively, indicating a close relationship.

Plesiomonas shigelloides was far from the other members of the family Vibrionaceae (Fig. 2). The location of this species was rather close to the locations of family Aeromonadaceae and $E$. coli.

Another outstanding feature of the results of our $16 \mathrm{~S}$ rRNA sequence analysis was that each bacterial genus had its own specific sequence pattern that was common to the species in that genus. These common sequences which characterized each genus are indicated in Fig. 1. For example, all three species of the genus Photobacterium had common sequences which were not identical to base sequences of other genera; they were $U, G-A-C, U, C, G$, $\mathrm{CA}$, and $\mathrm{A}$ at positions 307,379 to $384,443,455,459,473$ to 474, and 491, respectively. The genus Aeromonas had a specific sequence pattern characterized by G-A--C, G, C, A-..--A--U, C, and UG-....-.U at positions 379 to 384, $408,434,445$ to 456,463 , and 478 to 489 , respectively. 


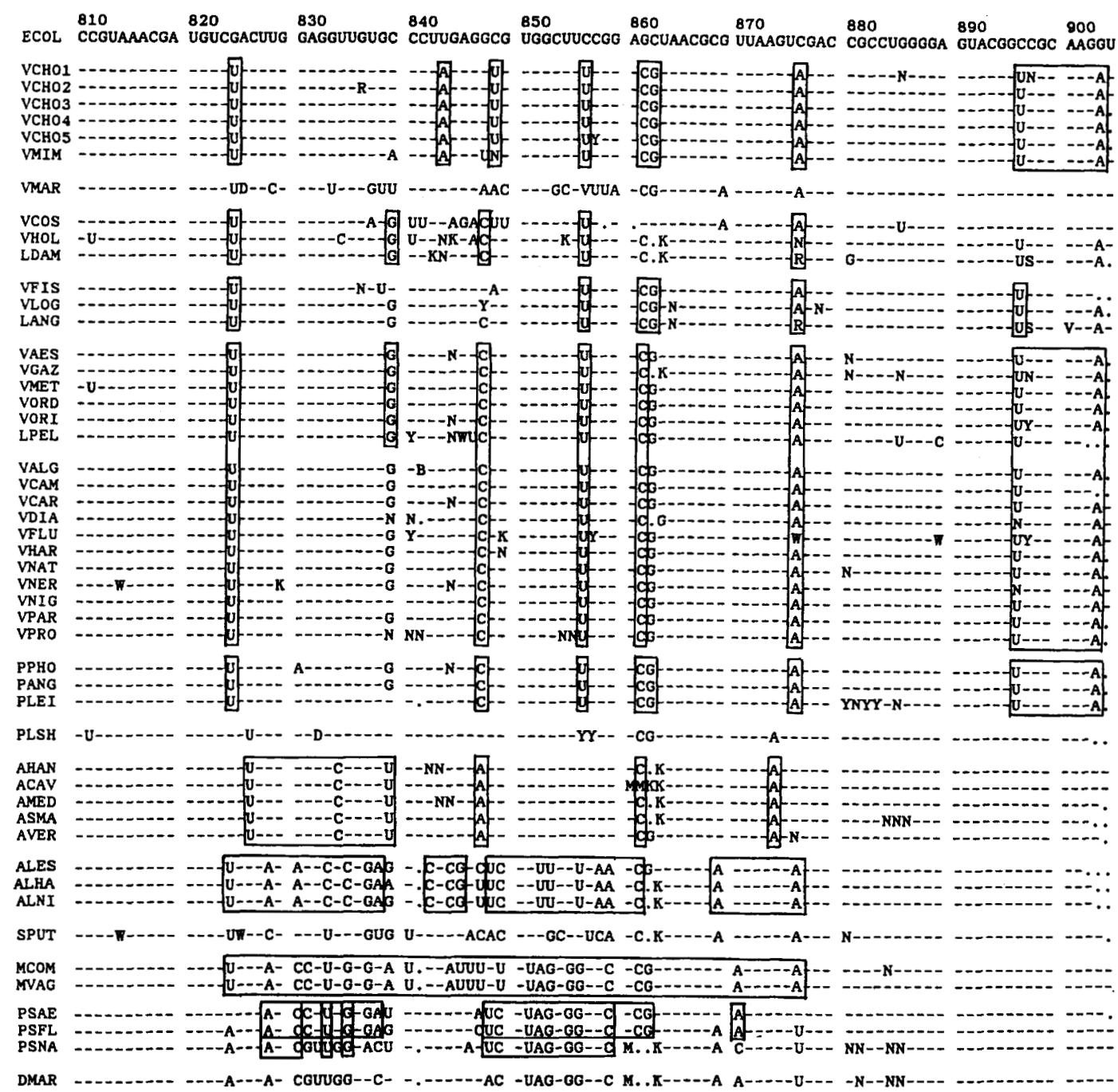

FIG. 1-Continued.

Likewise, the separate groups (genera) of the genus Vibrio and the genera Alteromonas, Marinomonas, and Pseudomonas had their own characteristic sequence patterns. If the vibrio groups were not separated, the common sequence patterns were less clear; in particular, the group had no common sequence at base positions 290 to 509, where all of the other genera had one or more common sequences. This result confirms the validity of separating the members of the genus Vibrio into several new genera. Also, our results suggest that the region of 16S rRNA from base positions 290 to 509 is evolutionarily more variable than the other two regions which we studied.

\section{DISCUSSION}

The phylogenetic relationships which we determined on the basis of a 16S rRNA sequence analysis of 50 reference strains conform to the current taxonomy of marine bacteria in many respects. For example, the genera Marinomonas, Alteromonas, and Shewanella are clearly distinguished from each other. The members of these three genera were placed together in the genus Alteromonas until 1983. The genus Shewanella was separated from the genus Alteromonas on the basis of the results of a 5S rRNA sequence analysis (22), and in 1983 the genus Marinomonas was distinguished from the genus Alteromonas as a result of data from a nucleic acid analysis (35). The genus-specific common sequence patterns (Fig. 1), as well as the similarity and $K$ values (Fig. 3), support the separation of these three genera.

The genus Aeromonas was once placed in the family Vibrionaceae. In 1986, Colwell et al. proposed a newly created family Aeromonadaceae on the basis of the results of $5 \mathrm{~S}$ rRNA sequencing; a member of the genus Aeromonas was the type species of this family (8). Figure 2 shows that species belonging to the genus Aeromonas form a branch that is clearly distinct from the other species of family Vibrionaceae. This result supports the proposal of Colwell et al.

On the other hand, our phylogenetic data also suggest that the current taxonomic system should be revised in many respects. Our $16 \mathrm{~S}$ rRNA sequence analysis revealed the clear phylogenetic divergence of the marine bacteria from their terrestrial counterparts. Three Pseudomonas species were used in this study, including one marine species, Pseudomonas nautica, which requires $\mathrm{Na}^{+}$for growth, and two terrestrial species, Pseudomonas fluorescens and 


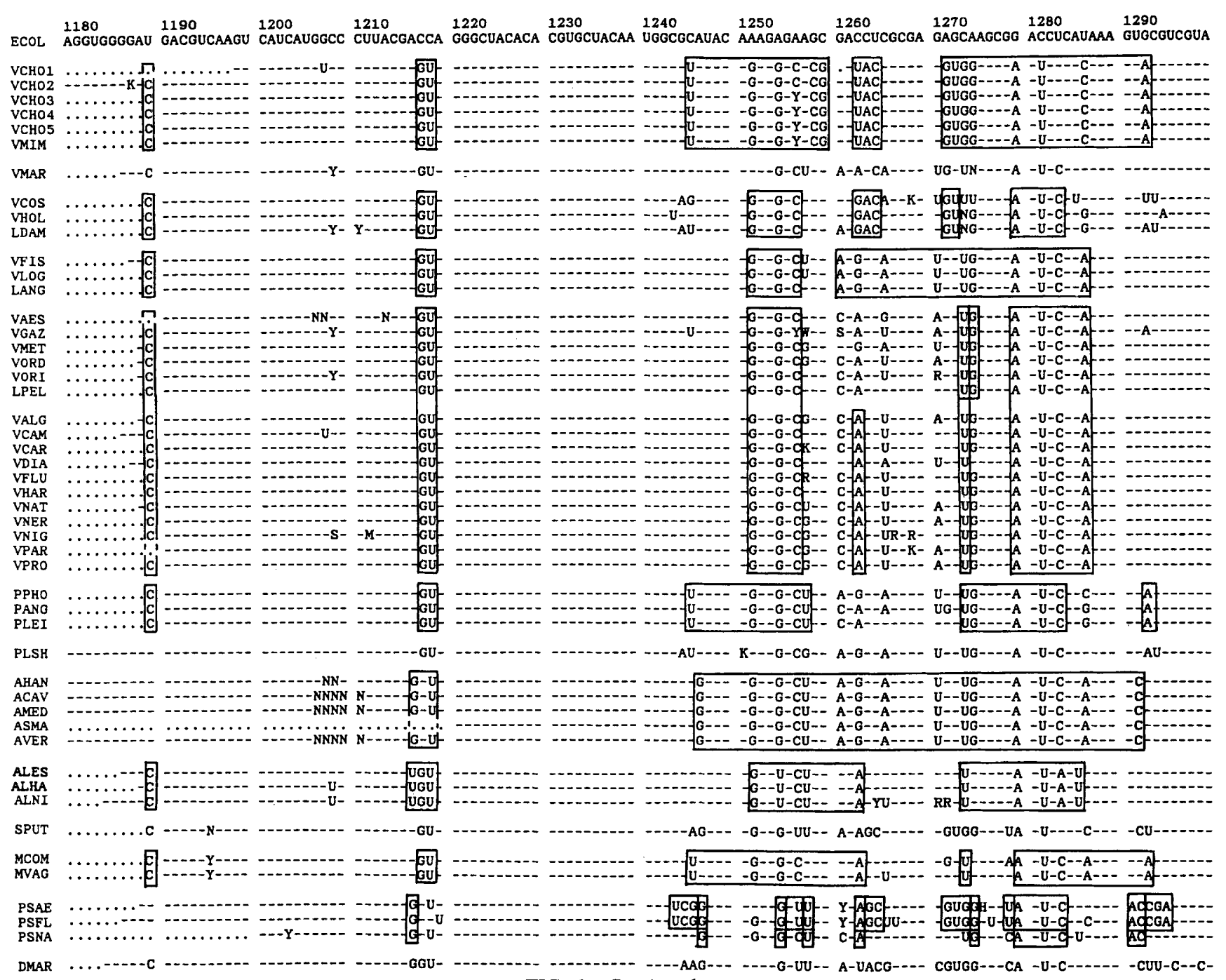

FIG. 1-Continued.

Pseudomonas aeruginosa, which do not require $\mathrm{Na}^{+}$. According to our phylogenetic analysis, Pseudomonas nautica is on a branch that is distinct from the branch containing the two terrestrial Pseudomonas species. Deleya marina, which was classified previously as Pseudomonas marina (24), requires $\mathrm{Na}^{+}$for growth, like Pseudomonas nautica. This species was also on a branch that was distinct from the terrestrial Pseudomonas species branch. Although additional study is needed, our results suggest that the halophilic, marine pseudomonads should be separated from the genus Pseudomonas and may be placed in newly created groups. The three species of the genus Pseudomonas had common, genus-specific sequence patterns. However, the two nonhalophilic strains shared far more and clearer common sequence patterns than all three species shared.

Subdivision of the family Vibrionaceae. A comparison of the phylogenetic relationships among 34 strains of the family Vibrionaceae suggested that the family should be separated into at least seven groups, which correspond to genera or families.

The first distinct group is $V$. marinus. MacDonell and Colwell have also suggested that $V$. marinus is significantly different from other vibrio species on the basis of its $5 \mathrm{~S}$
rRNA sequence (21). In 1990, Steven proposed that $V$. marinus should be renamed Moritella marinus on the basis of the results of molecular genetic methods, including $5 \mathrm{~S}$ rRNA sequencing and DNA-DNA hybridization (32). Our results based on 16S rRNA sequencing data support this proposal.

The second group comprises $V$. cholerae and $V$. mimicus. Whereas most species of the genus Vibrio require $\mathrm{Na}^{+}$, having optimal $\mathrm{Na}^{+}$concentrations of 2 to $3 \%, V$. cholerae, the type species of the genus Vibrio, is able to grow without $\mathrm{Na}^{+}$in the medium (2), although growth is stimulated by a small amount of $\mathrm{Na}^{+}$. In addition to the salt requirement, $V$. cholerae has many characteristics that distinguish it from other vibrio species. In this study, various strains of $V$. cholerae formed a tight cluster and were clearly separated from other species of the genus Vibrio. $V$. mimicus was proposed as an atypical strain of $V$. cholerae; these two taxa are very closely related both phenotypically and genotypically (DNA homology) (9).

The third group is composed of Vibrio costicola, Vibrio hollisae, and Listonella damsela. The members of this group are different from members of other groups and do not form a tight cluster. The similarity values and $K$ values for these 


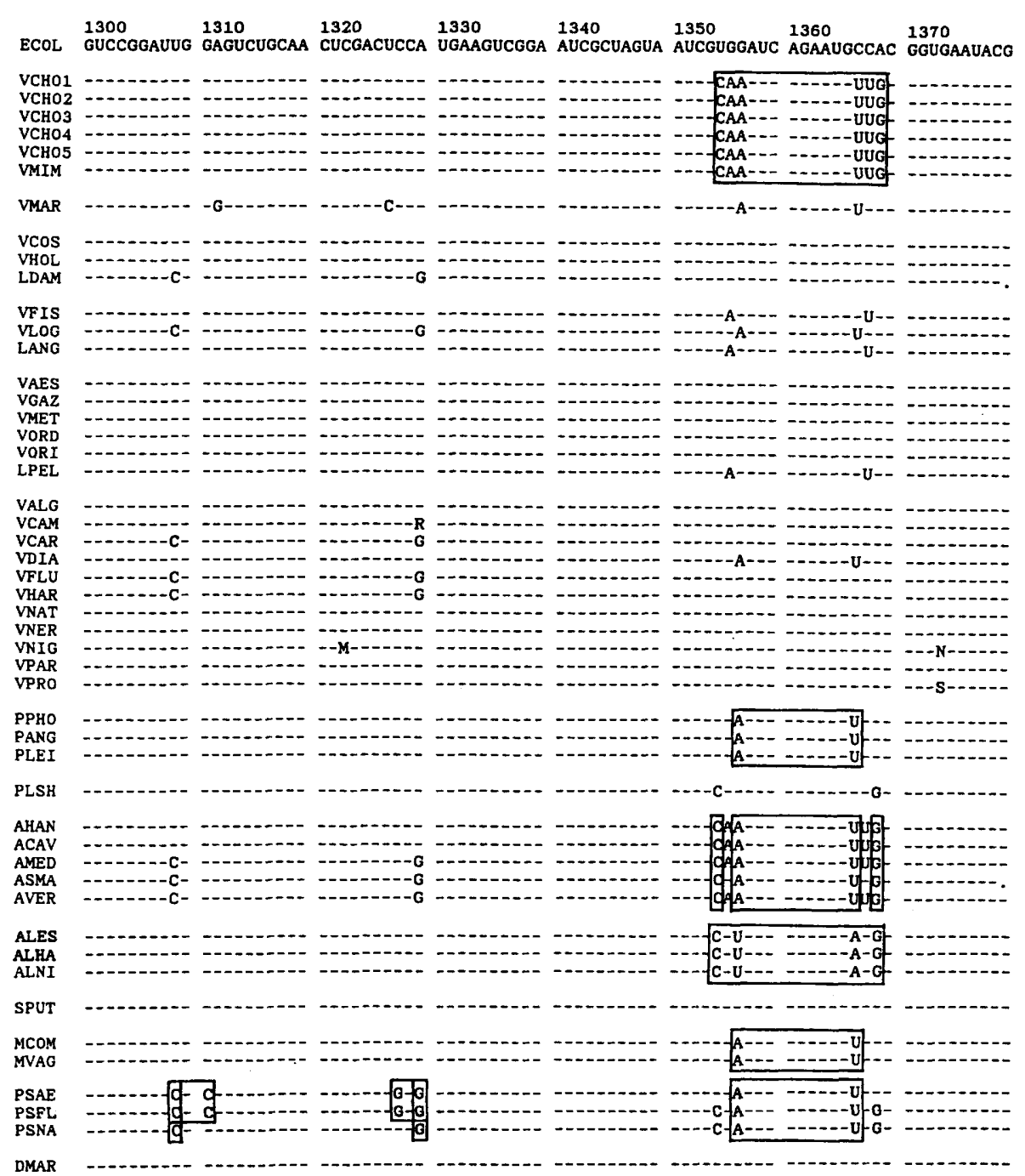

FIG. 1-Continued.

species range from 92.95 to $95.08 \%$ and from 5.37 to 7.40 , respectively. The similarity values are much lower than the values for species in other branches. We suggest that this group may be divided into two or three genera on the basis of phylogenetic relationships. Dorsch et al. also suggested that $V$. hollisae should be elevated to genus rank (11).

The fourth group, which also does not form a compact cluster, consists of three species, $V$. fischeri, $V$. logei, and $L$. anguillara. This group should be divided into different genera. Dorsch et al. suggested that $L$. anguillara should be separated from the other vibrio species (11). Two of these organisms, $V$. fischeri and $V$. logei, have the ability to luminesce. The other luminescent vibrio species, Vibrio harveyi and $V$. orientalis, fall into another branch, suggesting that luminescence is not a key criterion for distinguishing vibrio groups.

The fifth group consists of the genus Plesiomonas. Like the species of the family Aeromonadaceae, the genus Plesiomonas is placed by itself on a distinct branch. The levels of similarity between the genus Plesiomonas and groups belonging to the family Vibrionaceae are much lower than the levels of similarity between this genus and members of the family Aeromonadaceae or even E. coli. Our results support the suggestion of MacDonell and Colwell (22) that the genus Plesiomonas should be separated from the family Vibrionaceae. It seems that evolutionarily, Plesiomonas shigelloides is closely related to the family Aeromonadaceae and the family Enterobacteriaceae.

The sixth group comprises three species of the genus Photobacterium. The genus Vibrio and the genus Photobacterium have many common characteristics, but they can be separated on the basis of accumulation of poly- $\beta$-hydroxybutyrate and utilization of D-mannitol by Photobacterium species. These two genera are closely related, and the distinction between them based on phenotypic characteristics has often been a source of confusion. According to our data, a fairly clear separation of the two genera occurs on the phylogenetic tree (Fig. 2) and in similarity and distance matrices (Fig. 3).

The seventh group includes the remaining species of the family Vibrionaceae. Excluding $V$. cholerae, $V$. mimicus, $V$. costicola, $V$. hollisae, $L$. damsela, $V$. marinus, $V$. fischeri, $V$. logei, L. anguillara, and Plesiomonas shigelloides, the other 17 species of the Vibrionaceae form one large cluster. This group seems to be the main group of the genus Vibrio. Although the genus Listonella was separated from the genus 


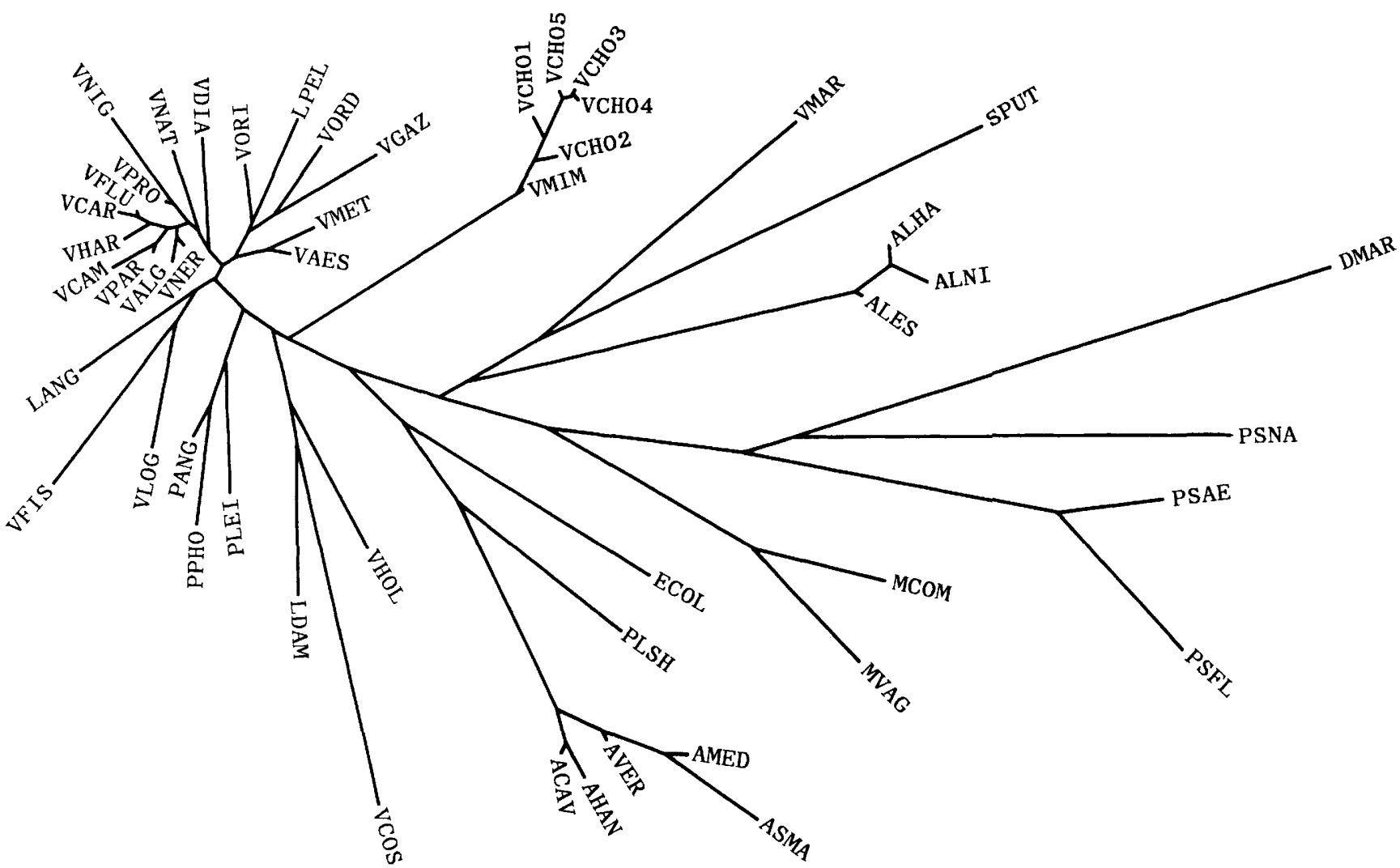

FIG. 2. Unrooted phylogenetic tree based on $16 \mathrm{~S}$ rRNA sequences, showing the relationships among the 50 reference strains which we used. For abbreviations of organism names, see Table 1.

Vibrio on the basis of $5 \mathrm{~S}$ rRNA sequences (22), according to the phylogenetic relationships based on a $16 \mathrm{~S}$ rRNA sequence analysis the species of the genus Listonella occur on three separate branches. A comparison of the common sequence patterns of the genus Vibrio and the genus Listonella showed that species of both genera have almost identical sequence patterns. According to our results, the genus Listonella is a rather heterogeneous group. Although further study, including a detailed comparison of 5S rRNA data, is needed, some species of the genus Listonella may be combined into genera which include species of the current genus Vibrio.

Criteria that separate taxa. In this study a phylogenetic analysis was performed by using 600 16S rRNA nucleotides and three universal primers (18) that have been used very frequently. Therefore, the similarity values and $K$ values should change when they are recalculated with the complete nucleotide sequences of the $16 \mathrm{~S}$ rRNAs. However, by comparing similarity values and $K$ values in this study, we arrived at a concept for distinguishing the taxonomic hierarchy on the basis of a 16S rRNA sequence analysis.

Within the seven groups on our phylogenetic tree, the similarity values and $K$ values ranged from 92.95 to $99.79 \%$ and from 0.22 to 7.40 , respectively. The lowest similarity value $(92.95 \%)$ and the highest $K$ value $(7.40)$ were obtained with the species $V$. costicola, $V$. hollisae, and $L$. damsela. When the branch containing these three species was excluded, the similarity values among the species of each group were more than $95 \%$ and the $K$ values were less than 5.00 , with one exception.
Our clustering, including subdivision of the current genus Vibrio, is in accord with the sequence patterns of the $16 \mathrm{~S}$ rRNAs. Each separate group on the phylogenetic tree has a common, characteristic sequence pattern. This is particularly clear when the grouped and ungrouped members of the genus Vibrio are compared. Our results indicate that the members of the genus Vibrio should be separated into at least five groups at the genus and family levels. From our observations of levels of interspecies similarity and distances among the genera, we concluded that the similarity values and $K$ values which separate different genera are 95 to $96 \%$ and 5.0 to 4.0 , respectively. If these values are adopted, the group consisting of $V$. costicola, $V$. hollisae, and $L$. damsela should be divided into two or three genera. Lower similarity values or higher distance values may indicate that the species should be separated into different genera, although other characteristics (e.g., phenotypic characteristics) of the species should also be taken into consideration before a final decision is made.

On the basis of a comparison of the distances among various families in Fig. 3, the similarity value which distinguishes different families is 90 to $91 \%$, and the $K$ value is 9 to 10. The similarity values and $K$ values among species within the current family Vibrionaceae range from 86.74 to $99.79 \%$ and from 0.22 to 14.71 , respectively. This means that the species of the Vibrionaceae are too diverse to be included in a single family. On the basis of our results, three species of the Vibrionaceae, $V$. marinus, $V$. costicola, and Plesiomonas shigelloides, are distant enough to create new families.

With respect to similarity values and $K$ values at the 


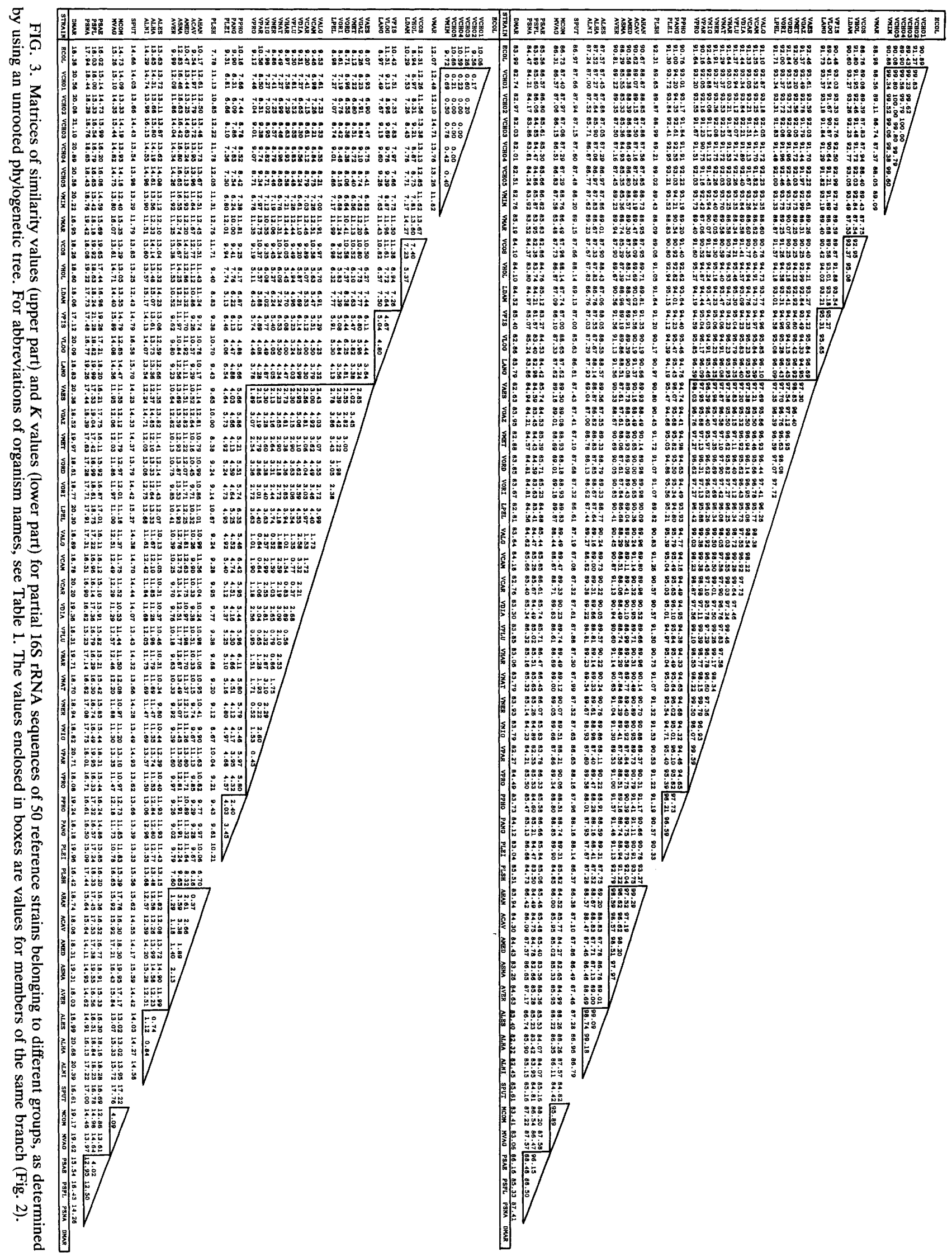


species level, multiple strains of only one species, $V$. cholerae, were compared in this study. The similarity values and $K$ values for these organisms were 99.23 to $100.00 \%$ and 0.00 to 0.60 , respectively. Therefore, we concluded that the $16 \mathrm{~S}$ rRNA similarity value and $K$ value that define a species are $99.2 \%$ and 0.6 , respectively. However, these values are valid only in this present study, since the values were obtained from a limited number of $16 \mathrm{~S}$ rRNA nucleotides. Also, the criteria for distinguishing species may vary in different taxonomic groups. Kawasaki (16a) has set a similarity value of $99.3 \%$ as the criterion for separating species on the basis of the results of a 16S rRNA sequence analysis for methanogens which belong to the archaebacteria. For $V$. mimicus, which was a member of a compact cluster along with five strains of $V$. cholerae, the similarity values and $K$ values in comparisons with the $V$. cholerae strains ranged from 99.06 to $99.60 \%$ and 0.40 to 0.78 , respectively. According to DNA-DNA relatedness data, $V$. mimicus is not related to $V$. cholerae at the species level (9). More data are needed to determine more accurate values for species differentiation.

The results of our $16 \mathrm{~S}$ rRNA sequence analysis showed that molecular genetic data are very valuable for establishing clear-cut definitions of various levels of bacterial taxa. However, more detailed studies will be needed to determine the exact similarity values or $K$ values which distinguish these taxa and to define species, subspecies, and biotypes that are very closely related phenetically and phylogenetically.

\section{ACKNOWLEDGMENTS}

We thank Y. Oyaizu-Masuchi for technical advice concerning sequencing of $16 \mathrm{~S}$ rRNA.

This investigation was supported by grants from the Ministry of Education of Japan and the Ministry of Agriculture, Forestry and Fisheries of Japan.

\section{REFERENCES}

1. Baumann, L., P. Baumann, M. Mendel, and R. D. Allen. 1972. Taxonomy of aerobic marine eubacteria. J. Bacteriol. 110:402429.

2. Baumann, P., and R. H. W. Schubert. 1984. Family II. Vibrionaceae, p. 516-550. In N. R. Krieg and J. G. Holt (ed.), Bergey's manual of systematic bacteriology, vol. 1. The Williams \& Wilkins Co., Baltimore.

3. Brayton, P. R., R. B. Bode, R. R. Colwell, M. T. MacDonell, H. L. Hall, D. J. Grimes, P. A. West, and T. N. Bryant. 1986. Vibrio cincinnatiensis sp. nov., a new human pathogen. J. Clin. Microbiol. 23:104-108.

4. Brenner, D. J., W. H.-B. Frances, J. V. Lee, A. G. Steigerwalt, G. R. Fanning, D. G. Hollis, J. J. Farmer III, R. E. Weaver, S. W. Joseph, and R. J. Seidler. 1983. Vibrio furnissii (formerly aerogenic biogroup of Vibrio fluvialis), a new species isolated from human feces and the environment. J. Clin. Microbiol. 18:816-824.

5. Brosius, J., J. L. Palmer, J. P. Kennedy, and H. F. Naler. 1978. Complete nucleotide sequence of a 16S ribosomal RNA gene from Escherichia coli. Proc. Natl. Acad. Sci. USA 75:48014805 .

6. Canard, B., T. Garnier, B. Lafay, R. Christen, and S. T. Cole. 1992. Phylogenetic analysis of the pathogenic anaerobe Clostridium perfringens using the 16S rRNA nucleotide sequence. Int. J. Syst. Bacteriol. 42:312-314.

7. Collins, M. D., S. Wallbanks, D. J. Lane, J. Shah, R. Nietupski, J. Smida, M. Dorsch, and E. Stackebrant. 1991. Phylogenetic analysis of the genus Listeria based on reverse transcriptase sequencing of 16S rRNA. Int. J. Syst. Bacteriol. 41:240-246.

8. Colwell, R. R., M. T. MacDonell, and J. De Ley. 1986. Proposal to recognize the family Aeromonadaceae fam. nov. Int. J. Syst. Bacteriol. 36:473-477.
9. Davis, B. R., G. R. Fanning, J. M. Madden, A. G. Steigerwalt, H. B. Bradford, Jr., H. L. Smith, Jr., and D. J. Brenner. 1981. Characterization of biochemically atypical Vibrio cholerae strains and designation of a new pathogenic species, Vibrio mimicus. J. Clin. Microbiol. 14:631-639.

10. Deming, J. W., L. K. Somers, W. L. Straube, D. G. Swartz, and M. T. MacDonell. 1988. Isolation of an obligatory barophilic bacterium and description of a new genus, Colwellia gen. nov. Syst. Appl. Microbiol. 10:152-160.

11. Dorsch, M., D. Lane, and E. Stackebrandt. 1992. Towards a phylogeny of the genus Vibrio based on 16S rRNA sequences. Int. J. Syst. Bacteriol. 42:58-63.

12. Egidius, E., R. Wiik, K. Andersen, K. A. Hoff, and B. Hjeltnes. 1986. Vibrio salmonicida sp. nov., a new fish pathogen. Int. J. Syst. Bacteriol. 36:518-520.

13. Grimes, D. J., J. Stemmler, H. Hada, E. B. May, D. Maneval, F. M. Hetrick, R. T. Jones, M. Stoskopf, and R. R. Colwell. 1984. Vibrio species associated with mortality of sharks held in captivity. Microb. Ecol. 10:271-282.

14. Guerinot, M. L., P. A. West, J. V. Lee, and R. R. Colwell. 1982. Vibrio diazotrophicus sp. nov., a marine nitrogen-fixing bacterium. Int. J. Syst. Bacteriol. 32:350-357.

15. Hada, H. S., P. A. West, J. V. Stemmler, and R. R. Colwell. 1984. Vibrio tubiashii sp. nov., a pathogen of bivalve molusks. Int. J. Syst. Bacteriol. 34:1-4.

16. Hickman, F. M., J. J. Farmer III, D. G. Hollis, G. R. Fanning, A. G. Steigerwalt, R. E. Weaver, and D. J. Brenner. 1982. Identification of Vibrio hollisae sp. nov. from patients with diarrhea. J. Clin. Microbiol. 15:395-401.

16a.Kawasaki, H. Personal communication.

17. Kimura, M. 1980. A simple method for estimating evolutionary rates of base substitutions through comparative studies of nucleotide sequences. J. Mol. Evol. 16:111-120.

18. Lane, D. J., B. Pace, G. J. Olsen, D. A. Stahl, M. L. Sogin, and N. R. Pace. 1985. Rapid determination of 16 S ribosomal RNA sequences for phylogenetic analyses. Proc. Natl. Acad. Sci. USA 82:6955-6959.

19. Lawson, P. A., S. E. Gharbia, H. N. Shah, D. R. Clark, and M. D. Collins. 1991. Intrageneric relationships of members of the genus Fusobacterium as determined by reverse transcriptase sequencing of small-subunit rRNA. Int. J. Syst. Bacteriol. 41:347-354.

20. Love, M., D. Teebken-Fisher, J. E. Hose, J. J. Farmer III, F. W. Hickman, and G. R. Fanning. 1981. Vibrio damsela, a marine bacterium, causes skin ulcers on the damselfish Chromis punctipinnis. Science 214:1139-1140.

21. MacDonell, M. T., and R. R. Colwell. 1984. The nucleotide sequence of 5S ribosomal RNA from Vibrio marinus. Microbiol. Sci. 1:229-231.

22. MacDonell, M. T., and R. R. Colwell. 1985. Phylogeny of the Vibrionaceae and recommendation for two new genera, Listonella and Shewanella. Syst. Appl. Microbiol. 6:171-182.

23. Maniatis, T., E. F. Fritsch, and J. Sambrook. 1982. Molecular cloning: a laboratory manual. Cold Spring Harbor Laboratory, Cold Spring Harbor, N.Y.

24. Palleroni, N. J. 1984. Pseudomonas, p. 141-199. In N. R. Krieg and J. G. Holt (ed.), Bergey's manual of systematic bacteriology, vol. 1. The Williams \& Wilkins Co., Baltimore.

25. Paster, B. J., A. Lee, J. G. Fox, F. E. Dewhirst, L. A. Tordoff, G. J. Fraser, J. L. O'Rourke, N. S. Taylor, and R. Ferrero. 1991. Phylogeny of Helicobacter felis sp. nov., Helicobacter mustelae, and related bacteria. Int. J. Syst. Bacteriol. 41:31-38.

26. Pujalte, M.-J., and E. Garay. 1986. Proposal of Vibrio mediterranei $\mathrm{sp}$. nov.: a new marine member of the genus Vibrio. Int. J. Syst. Bacteriol. 36:278-281.

27. Saitou, N., and M. Nei. 1987. The neighbor-joining method: a new method for reconstructing phylogenetic trees. Mol. Biol. Evol. 4:406-425.

28. Schiewe, M. H., T. J. Trust, and J. H. Crosa. 1981. Vibrio ordalii sp. nov.: a causative agent of vibriosis in fish. Curr. Microbiol. 6:343-348.

29. Shewan, J. M., and M. Veron. 1974. Genus 1. Vibrio, p. 340-345. In R. E. Buchanan and N. E. Gibbous (ed.), Bergey's 
manual of determinative bacteriology, 8th ed. The Williams \& Wilkins Co., Baltimore.

30. Simidu, U., E. Kaneko, and N. Taga. 1977. Microbiological studies of Tokyo Bay. Microb. Ecol. 3:173-191.

31. Simidu, U., N. Taga, R. R. Colwell, and J. R. Schwartz. 1980. Heterotrophic bacterial flora of the seawater from the Nansei Shoto (Ryukyu Retto) area. Bull. Jpn. Soc. Sci. Fish. 46:505510.

32. Steven, S. E. 1990. Molecular systematics of Vibrio and Photobacterium. Ph. D. dissertation. University of Maryland, College Park.

33. Tison, D. L., and R. J. Seidler. 1983. Vibrio aestuarianus: a new species from estuarine waters and shellfish. Int. J. Syst. Bacteriol. 33:699-702.

34. Urdaci, M. C., M. Marchand, E. Ageron, J. M. Arcos, B. Sesma, and P. A. D. Grimont. 1991. Vibrio navarrensis sp. nov., a species from sewage. Int. J. Syst. Bacteriol. 41:290-294.
35. Van Landschoot, A., and J. De Ley. 1983. Intra- and intergeneric similarities of the rRNA cistrons of Alteromonas, Marinomonas (gen. nov.) and some other gram-negative bacteria. J. Gen. Microbiol. 129:3057-3074.

36. Wayne, L. G., D. J. Brenner, R. R. Colwell, P. A. D. Grimont, O. Kandler, M. I. Krichevsky, L. H. Moore, W. E. C. Moore, R. G. E. Murray, E. Stackebrandt, M. P. Starr, and H. G. Truper. 1987. Report of the Ad Hoc Committee on Reconciliation of Approaches to Bacterial Systematics. Int. J. Syst. Bacteriol. 37:463-464.

37. Yang, Y., L. P. Yeh, Y. Cao, L. Baumann, P. Baumann, J. S. Tang, and B. Beaman. 1983. Characterization of marine luminous bacteria isolated off the coast of China and description of Vibrio orientalis sp. nov. Curr. Microbiol. 8:95-100.

38. ZoBell, C. E. 1946. Marine microbiology. Chronica Botanica Co., Waltham, Mass. 